\title{
Analysis of oxygen uptake efficiency parameters in young people with cystic fibrosis
}

\author{
Owen W. Tomlinson ${ }^{1,2} \cdot$ Alan R. Barker ${ }^{1} \cdot$ Lucy V. Chubbock $^{1} \cdot$ Daniel Stevens $^{3} \cdot$ Zoe L. Saynor $^{4,5} \cdot$ Patrick J. Oades $^{2}$. \\ Craig A. Williams ${ }^{1,2}$
}

Received: 19 February 2018 / Accepted: 25 June 2018 / Published online: 12 July 2018

(c) The Author(s) 2018

\begin{abstract}
Purpose This study characterised oxygen uptake efficiency (OUE) in children with mild-to-moderate cystic fibrosis (CF). Specifically, it investigated (1) the utility of OUE parameters as potential submaximal surrogates of peak oxygen uptake $\left(\dot{V} \mathrm{O}_{\text {2peak }}\right)$, and (2) the relationship between OUE and disease severity.

Methods Cardiopulmonary exercise test (CPET) data were collated from 72 children [36 CF, 36 age- and sex-matched controls (CON)], with OUE assessed as its highest 90-s average (plateau; OUEP), the gas exchange threshold (OUE $\mathrm{GET}_{\mathrm{GET}}$ and respiratory compensation point $\left(\mathrm{OUE}_{\mathrm{RCP}}\right)$. Pearson's correlation coefficients, independent $t$ tests and factorial ANOVAs assessed differences between groups and the use of OUE measures as surrogates for $\dot{V} \mathrm{O}_{2 \text { peak }}$.

Results A significant $(p<0.05)$ reduction in allometrically scaled $\dot{V} \mathrm{O}_{2 \text { peak }}$ and all OUE parameters was found in CF. Significant $(p<0.05)$ correlations between measurements of OUE and allometrically scaled $\dot{V} \mathrm{O}_{2 \text { peak }}$, were observed in CF $(r=0.49-0.52)$ and CON $(r=0.46-0.52)$. Furthermore, measures of OUE were significantly $(p<0.05)$ correlated with pulmonary function ( $\left.\mathrm{FEV}_{1 \% \text { predicted }}\right)$ in CF $(r=0.38-0.46)$, but not CON $(r=-0.20-0.14)$. OUEP was able to differentiate between different aerobic fitness tertiles in CON but not CF.

Conclusions OUE parameters were reduced in CF, but were not a suitable surrogate for $\dot{V} \mathrm{O}_{2 \text { peak }}$. Clinical teams should, where possible, continue to utilise maximal CPET parameters to measure aerobic fitness in children and adolescents with CF. Future research should assess the prognostic utility of OUEP as it does appear sensitive to disease status and severity.
\end{abstract}

Keywords Adolescence $\cdot$ Aerobic fitness $\cdot$ Exercise testing $\cdot$ Paediatrics $\cdot$ Respiratory disease

\section{Abbreviations}

CF $\quad$ Cystic fibrosis

CON Control

CPET Cardiopulmonary exercise test

ES Effect size

$\mathrm{FEV}_{1} \quad$ Forced expiratory volume in $1 \mathrm{~s}$
FVC Forced vital capacity

GET Gas exchange threshold

OUE Oxygen uptake efficiency

OUEP Oxygen uptake efficiency plateau

OUE $_{\text {GET }}$ Oxygen uptake efficiency at the gas exchange threshold
Communicated by Peter Krustrup.

Craig A. Williams

c.a.williams@exeter.ac.uk

1 Children's Health and Exercise Research Centre, Sport and Health Science, College of Life and Environmental Sciences, University of Exeter, St Luke's Campus, Heavitree Road, Exeter EX1 2LU, UK

2 Royal Devon and Exeter NHS Foundation Trust Hospital, Barrack Road, Exeter EX2 5DW, UK

3 Division of Respirology, Department of Pediatrics, Faculty of Medicine and School of Health and Human Performance, Faculty of Health Professions, Dalhousie
University, Stairs House, 6230 South St., PO BOX 15000 , Halifax NS B3H 4R2, Canada

4 Department of Sport and Exercise Science, Faculty of Science, University of Portsmouth, Spinnaker Building, Cambridge Road, Portsmouth PO1 2ER, UK

5 Paediatric and Adult Respiratory Departments, University Hospital Southampton, Tremona Road, Southampton SO16 6YD, UK 


$\begin{array}{ll}\text { OUE }_{\mathrm{RCP}} & \begin{array}{l}\text { Oxygen uptake efficiency at the respiratory } \\ \text { compensation point }\end{array} \\ \text { OUES } & \text { Oxygen uptake efficiency slope } \\ \mathrm{RCP} & \text { Respiratory compensation point } \\ \dot{V} \mathrm{O}_{2} & \text { Volume of oxygen uptake }\end{array}$

\section{Introduction}

It is well established that a high level of aerobic fitness, typically characterised by peak oxygen uptake $\left(\dot{V} \mathrm{O}_{2 \text { peak }}\right)$, is of benefit for young people with cystic fibrosis (CF). A higher $\dot{V} \mathrm{O}_{2 \text { peak }}$ is associated with an improved quality of life (Hebestreit et al. 2014), reduced risk of hospitalisation for pulmonary exacerbations (Pérez et al. 2014) and reduced mortality risk (Nixon et al. 1992; Pianosi et al. 2005). As a result, regular cardiopulmonary exercise testing (CPET) is recommended by the European CF Society and endorsed by the European Respiratory Society (Hebestreit et al. 2015), to monitor changes in aerobic fitness and guide decisions concerning clinical status and therapeutic interventions.

CPET is considered the gold standard method to assess aerobic fitness, with assessment of $\dot{V} \mathrm{O}_{2 \text { peak }}$ requiring the individual to provide a maximal physical effort. Factors such as excessive dyspnoea and/or a lack of motivation may cause individuals with $\mathrm{CF}$ to be unwilling or unable to reach volitional exhaustion and thus $\dot{V} \mathrm{O}_{2 \text { peak }}$. It has, therefore, been proposed that submaximal markers of aerobic fitness should be investigated as viable alternatives that can provide clinically useful information in such circumstances (Williams et al. 2014).

Previous research has shown the oxygen uptake efficiency slope (OUES) (Baba et al. 1996) to be a potentially useful submaximal parameter of aerobic fitness due to its high correlation with $\dot{V} \mathrm{O}_{2 \text { peak }}$ in clinical populations, including adults with CF (Gruet et al. 2010). However, there are several issues that preclude the use of OUES as an alternative marker of aerobic fitness in CF. First, OUES is dependent on body size and requires allometric scaling to normalise data (Tomlinson et al. 2017) - a process that may be time consuming in clinical practice. Second, the OUES has a high level of variability [as measured by coefficients of variation (CV)], both between participants, and in terms of test-retest reproducibility in healthy adults (Sun et al. 2012b) and children (Bongers et al. 2015). Finally, the OUES is unable to discriminate aerobic fitness within children and adolescents with mild-to-moderate CF (Williams et al. 2018).

The utility of other submaximal CPET parameters in children with $\mathrm{CF}$, such as oxygen uptake efficiency (OUE) - the ratio between oxygen uptake $\left(\dot{V} \mathrm{O}_{2}\right)$ and ventilation $\left(\dot{V}_{\mathrm{E}}\right)\left[\dot{V} \mathrm{O}_{2}\right.$ $/ \dot{V}_{\mathrm{E}}$ (Sun et al. 2012b)]—-therefore, warrants consideration. Unlike the OUES, which utilises a log-transformation of $\dot{V}_{\mathrm{E}}$ (Baba et al. 1996) to linearise the non-linear ventilatory profile often observed during incremental exercise, the OUE parameter accommodates this curvilinear relationship between $\dot{V}_{\mathrm{E}}$ and $\dot{V} \mathrm{O}_{2}$ (Bongers et al. 2015). Furthermore, OUE has been shown to have less variability (CV) than OUES within groups of adults (39.5 vs. 14.6\%) (Sun et al. 2012b) and children (32.9 vs. 10.9\%) (Bongers et al. 2015) and is not dependent on body size (Sun et al. 2012b). This independence of body size, therefore, removes potential bias due to growth and the subsequent need to scale data, which may be of further benefit in a clinical setting.

Practically, OUE can be measured at any point during an incremental exercise test. However, the highest 90-second (s) plateau (oxygen uptake efficiency plateau; OUEP), which typically occurs prior to, or at, the ventilatory threshold (VT) (Bongers et al. 2015) or gas exchange threshold (GET) (Sun et al. 2012b), has been shown to be a predictor of mortality in heart failure (Sun et al. 2012a). Despite demonstrated clinical utility in cardiac populations, its role in chronic respiratory disease remains unknown. Furthermore, given that the ratio of $\dot{V}_{\mathrm{E}}$ to $\dot{V} \mathrm{O}_{2}$ (ventilatory equivalent for oxygen) at peak exercise has been shown to be a more significant predictor of mortality in children and adolescents with CF than body mass relative $\dot{V} \mathrm{O}_{2 \text { peak }}$ (Hulzebos et al. 2014), it is clear that the relationship between $\dot{V}_{\mathrm{E}}$ and $\dot{V} \mathrm{O}_{2}$ is of clinical significance, and warrants further investigation, particularly when it is not feasible nor possible to assess $\dot{V} \mathrm{O}_{2 \text { peak }}$, e.g. due to pathophysiological or motivational reasons. Therefore, the OUE (and in particular the OUEP) has the potential to be considered submaximal measures of aerobic fitness that could be used to quantify pathophysiological and/or therapeutically induced changes. However, evidence for this utilisation of OUE is required, with recent research calling for further investigation into the prognostic properties of other OUE parameters in children and adolescents with chronic health conditions, such as CF (Bongers et al. 2015).

Therefore, the aim of this study was to explore the utility of OUE parameters, in children and adolescents with mild-tomoderate $\mathrm{CF}$, as potential submaximal surrogates for $\dot{V} \mathrm{O}_{2 \text { peak }}$. This is conducted first by characterising the OUE responses during CPET in children and adolescents with mild-to-moderate $\mathrm{CF}$, compared with age- and sex-matched controls; second, by assessing the utility of OUE as an objective, submaximal surrogate for $\dot{V} \mathrm{O}_{2 \text { peak }}$ in this population; third, identifying the relationship between OUE parameters and disease status and severity in individuals with CF.

\section{Methods}

\section{Participants}

Data from 72 children and adolescents (36 with mild-tomoderate $\mathrm{CF}$ and 36 age- and sex-matched $\mathrm{CON}$; 21 males 
per group; mean age $13.3 \pm 2.8$ years) were included in this study. Participant characteristics are presented in Table 1.

\section{Ethics approval}

This study was a retrospective analysis of existing data, and, therefore, did not require additional ethics approval. Ethics approval for original data collected was approved by the South West NHS Research Ethics Committee and the University of Exeter Sport and Health Sciences Ethics Committee. Fully informed written consent and assent were

Table 1 Anthropometric, pulmonary function and exercise-related differences between $\mathrm{CF}$ and $\mathrm{CON}$ groups

\begin{tabular}{|c|c|c|c|c|}
\hline Variable & $\mathrm{CF}$ & $\mathrm{CON}$ & $p$ value & ES \\
\hline Age (years) & $13.4(2.7)$ & $13.2(2.9)$ & 0.77 & 0.08 \\
\hline Stature $(\mathrm{cm})$ & $155.6(13.5)$ & $159.1(15.2)$ & 0.32 & 0.24 \\
\hline Body mass (kg) & $50.15(15.46)$ & $51.15(14.49)$ & 0.78 & 0.07 \\
\hline BMI $\left(\mathrm{kg} \mathrm{m}^{-2}\right)$ & $20.28(3.67)$ & $19.91(4.18)$ & 0.70 & 0.09 \\
\hline $\operatorname{BSA}\left(\mathrm{m}^{2}\right)$ & $1.46(0.28)$ & $1.49(0.28)$ & 0.65 & 0.11 \\
\hline $\mathrm{FEV}_{1}(\mathrm{~L})^{*}$ & $2.46(0.97)$ & $2.96(0.86)$ & 0.07 & 0.55 \\
\hline $\mathrm{FEV}_{1}\left(\%_{\text {predicted }}\right)^{*}$ & $85.0(20.0)$ & $97.5(10.6)$ & 0.004 & 0.71 \\
\hline $\mathrm{FVC}(\mathrm{L}) *$ & $3.10(1.14)$ & $3.44(1.02)$ & 0.30 & 0.31 \\
\hline FVC $\left(\%_{\text {predicted }}\right) *$ & $92.7(16.6)$ & $98.6(11.0)$ & 0.18 & 0.39 \\
\hline $\operatorname{MVV}\left(\mathrm{L} \mathrm{min}^{-1}\right)^{*}$ & $86.2(34.0)$ & $103.6(30.0)$ & 0.07 & 0.53 \\
\hline$\dot{V} \mathrm{O}_{\text {2peak }}\left(\mathrm{L} \mathrm{min}^{-1}\right)$ & $1.74(0.57)$ & $2.03(0.88)$ & 0.09 & 0.39 \\
\hline $\begin{array}{l}\dot{V} \mathrm{O}_{2 \text { peak }}\left(\mathrm{mL} \mathrm{kg}^{-1}\right. \\
\left.\min ^{-1}\right)\end{array}$ & $37.74(7.74)$ & 39.93 (10.70) & 0.32 & 0.23 \\
\hline $\begin{array}{l}\dot{V} \mathrm{O}_{2 \text { peak }}(\mathrm{mL} \\
\left.\mathrm{kg}^{-0.86} \mathrm{~min}^{-1}\right)\end{array}$ & 74.62 & $84.94(23.51)$ & 0.031 & 0.52 \\
\hline $\begin{array}{l}\text { Relative } \dot{V} \mathrm{O}_{2 \text { peak }} \\
\left(\%_{\text {predicted }}\right)\end{array}$ & $83.3(16.8)$ & $87.8(20.8)$ & 0.32 & 0.24 \\
\hline $\operatorname{GET}\left(\mathrm{L} \min ^{-1}\right)$ & $0.91(0.28)$ & $1.12(0.54)$ & 0.035 & 0.49 \\
\hline $\operatorname{GET}\left(\% \dot{V} \mathrm{O}_{2 \text { peak }}\right)$ & $53.4(9.3)$ & $55.0(8.0)$ & 0.42 & 0.18 \\
\hline $\mathrm{HR}_{\max }$ (beats $\min ^{-1}$ ) & $182(8)$ & $185(14)$ & 0.30 & 0.26 \\
\hline$\dot{V}_{\mathrm{Emax}}\left(\mathrm{L} \min ^{-1}\right)$ & 74.66 (35.62) & $69.18(33.45)$ & 0.50 & 0.16 \\
\hline$\dot{V}_{\text {Emax }}(\% \mathrm{MVV})^{*}$ & $88.3(30.4)$ & $60.9(23.3)$ & 0.001 & 0.97 \\
\hline OUEP $\left(\mathrm{mL} \mathrm{L}^{-1}\right)$ & $35.58(5.40)$ & $45.09(5.78)$ & $<\mathbf{0 . 0 0 1}$ & 1.70 \\
\hline $\operatorname{OUE}_{\mathrm{GET}}\left(\mathrm{mL} \mathrm{L}^{-1}\right)$ & $34.08(5.40)$ & $43.24(5.08)$ & $<0.001$ & 1.75 \\
\hline $\operatorname{OUE}_{\mathrm{RCP}}\left(\mathrm{mL} \mathrm{L}^{-1}\right)$ & $29.49(4.95)$ & $35.15(4.52)$ & $<0.001$ & 1.19 \\
\hline OUEP $\left(\%_{\text {predicted }}\right)$ & $83.2(13.9)$ & $105.7(13.0)$ & $<0.001$ & 1.68 \\
\hline
\end{tabular}

Measures are presented as mean $( \pm S D)$. Significant mean differences are denoted by a bold $p$ value. *Unequal groups for pulmonary variables: $\mathrm{CF}=36, \mathrm{CON}=18$

$B M I$ body mass index, $B S A$ body surface area, $F E V_{1}$ forced expiratory volume in $1 \mathrm{~s}, F V C$ forced vital capacity, $M V V$ maximal voluntary ventilation, $\dot{V} O_{2}$ volume of oxygen uptake, GET gas exchange threshold, $H R$ heart rate, $\dot{V}_{E}$, minute ventilation, $R E R$ respiratory exchange ratio, $O U E P$ oxygen uptake efficiency plateau, $O U E_{G E T}$ oxygen uptake efficiency at the gas exchange threshold, $O U E_{R C P}$ oxygen uptake efficiency at the respiratory compensation point, $E S$ effect size obtained from parents/guardians and paediatric participants, respectively.

\section{Anthropometric variables}

Stature was measured to the nearest $0.001 \mathrm{~m}$ using a stadiometer (Holtain Ltd., Crymych, UK) and body mass to the nearest $0.01 \mathrm{~kg}$ using digital scales (Seca, Birmingham, UK). Body mass index (BMI) was subsequently calculated, and body surface area (BSA) was estimated using the Haycock equation (Haycock et al. 1978).

\section{Pulmonary function}

Pulmonary function was assessed using flow-volume loop spirometry, with the maximal values from three acceptable manoeuvres for forced expiratory volume in $1 \mathrm{~s}\left(\mathrm{FEV}_{1}\right)$ and forced vital capacity (FVC) expressed relative to normative reference values from the Global Lung Function Initiative (Quanjer et al. 2012). Maximal voluntary ventilation (MVV) was calculated by multiplying $\mathrm{FEV}_{1}$ (L) by 35 (Wasserman et al. 2005).

\section{Exercise variables}

All participants undertook a CPET to volitional exhaustion on an electronically braked cycle ergometer (Lode, the Netherlands) to determine maximal and submaximal measures of aerobic fitness. Breath-by-breath changes in pulmonary gas exchange and ventilation were measured, and subsequently averaged to 10 -s time intervals. Of the 72 participants within the study, 33 children ( $20 \mathrm{CF}, 13 \mathrm{CON})$ undertook a previously described supramaximal verification bout to determine a 'true' $\dot{V} \mathrm{O}_{2 \text { peak }}$ (Barker et al. 2011; Saynor et al. 2013a). However, as not all participants underwent this verification testing, the highest $\dot{V} \mathrm{O}_{2}$ obtained during the course of testing procedures is referred to as ' $\dot{V} \mathrm{O}_{2 \text { peak }}$ '. Following determination of $\dot{V} \mathrm{O}_{2 \text { peak }}$, the GET and respiratory compensation point (RCP) were independently verified by two researchers using methods described by Beaver et al. (1986) - the disproportionate increases in $\dot{V} \mathrm{CO}_{2}$ relative to $\dot{V} \mathrm{O}_{2}$ (i.e. $V$ slope method for GET) and $\dot{V}_{\mathrm{E}}$ relative to $\dot{V} \mathrm{CO}_{2}$ for RCP. This process is reliable in children with $\mathrm{CF}[\mathrm{CV}=11.2 \%$, Saynor et al. (2013b)], and those without $\mathrm{CF}[\mathrm{CV}=7.5 \%$, Fawkner et al. (2002)]. $\dot{V} \mathrm{O}_{2 \text { peak }}$ was compared to normative reference values, chosen due their similar participant characteristics and methodology, whilst also accounting for age and sex (Bongers et al. 2014a), and split into aerobic fitness tertiles [a division shown to predict mortality in CF (Pianosi et al. 2005)] for each group. Reliability of all gaseous exchange variables for children and adolescents with CF (Saynor et al. 2013b), and without CF (Welsman et al. 2005; Bongers et al. 2015), have previously been reported. 
OUE values were calculated in line with previous work (Sun et al. 2012b), and were obtained by averaging $\dot{V} \mathrm{O}_{2} / \dot{V}_{\mathrm{E}}$ in the $60 \mathrm{~s}$ prior to the GET (OUE $\left.\mathrm{OET}_{\mathrm{GET}}\right)$ and $\mathrm{RCP}\left(\mathrm{OUE}_{\mathrm{RCP}}\right)$. The OUEP was taken as the highest $90 \mathrm{~s} \dot{V} \mathrm{O}_{2} / \dot{V}_{\mathrm{E}}$ average. Warm-up and cool-down data during exercise were omitted from data analysis to isolate the incremental profile of the CPET. OUEP was also compared to normative values (Bongers et al. 2014a, 2015).

\section{Statistical analyses}

Statistical analyses were performed using IBM SPSS Statistics v23 (IBM Corp., Armonk NY, USA). Allometric scaling was utilised to remove the influence of body mass from $\dot{V} \mathrm{O}_{2 \text { peak }}$ in both CF and CON groups (Welsman et al. 1996). Scaling of OUE variables was not required as there were no significant relationships with body size, thereby indicating size independence, as previously reported in adults (Sun et al. 2012b).

Pearson's correlation coefficients determined relationships between all OUE parameters and $\dot{V} \mathrm{O}_{2 \text { peak, }}$ as well as, the traditional clinical marker of disease severity, $\mathrm{FEV}_{1}$ (expressed as a percentage of predicted). Independent sample $t$ tests established mean differences in anthropometric, pulmonary function and CPET parameters between groups. Factorial analyses of variance (ANOVAs) were used to establish interaction effects between disease status and aerobic fitness tertiles (as described in 'Exercise variables') upon $\dot{V} \mathrm{O}_{2 \text { peak }}$ and OUE parameters. For ANOVAs, the tertiles for $\dot{V} \mathrm{O}_{2 \text { peak }}$ to which participants were categorised (i.e. high, middle, low) remained the same throughout all ANOVAs, regardless of OUE value. Where significant effects occurred, planned pairwise comparisons with a Sidak correction factor were applied, chosen for its correction of multiple comparisons (reducing Type 1 error), whilst simultaneously being less conservative than Bonferroni corrections (thus reducing Type 2 error) (Abdi 2007). Statistical significance was set at an alpha level of 0.05, and effect sizes (ES) for mean comparisons were described using Cohen's thresholds $($ small $=0.2$, medium $=0.5$, large $=0.8)($ Cohen 1992 $)$.

\section{Results}

\section{Differences in OUE between groups}

All OUE outcomes were detected in 68/72 participants

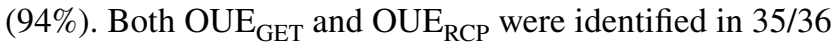
(97\%) of children and adolescents in the CF group. In the CON group, $\mathrm{OUE}_{\mathrm{GET}}$ was detected in all participants (36/36, $100 \%$ ), and $\mathrm{OUE}_{\mathrm{RCP}}$ was detected in 34/36 (94\%) of participants. The profiles of OUEP, OUE $\mathrm{GET}_{\text {and }}$ OUE $\mathrm{RCP}_{\mathrm{R}}$ during a CPET for a representative individual with $\mathrm{CF}$ are shown in Fig. 1. A representative comparison of OUEP for one participant with $\mathrm{CF}$ against $\mathrm{CON}$ is shown in Fig. 2.

Differences between groups were observed for pulmonary function, absolute GET, $\mathrm{OUE}_{\mathrm{GET}}, \mathrm{OUE}_{\mathrm{RCP}}$ and OUEP, with $\mathrm{CON}$ being significantly higher than $\mathrm{CF}$. No significant difference was observed between $\mathrm{CF}$ and $\mathrm{CON}$ groups for $\dot{V} \mathrm{O}_{2 \text { peak }}$, when expressed as an absolute value. However, the CON group was revealed to have a significantly $(p<0.05)$ greater $\dot{V} \mathrm{O}_{2 \text { peak }}$ when allometric scaling had removed residual effects of body size (Table 1). Individual differences between age- and sex-matched pairs for $\dot{V} \mathrm{O}_{2 \text { peak }}$ and OUEP are displayed in Fig. 3.

\section{Correlation of with OUE with $\mathrm{VO}_{2 \text { peak }}$}

OUEP and $\mathrm{OUE}_{\mathrm{GET}}$ were significantly and positively correlated with absolute $\dot{V} \mathrm{O}_{2 \text { peak }}$ in the $\mathrm{CF}$ and $\mathrm{CON}$ groups; however, OUE $\mathrm{RCP}_{\mathrm{R}}$ was not correlated with absolute $\dot{V} \mathrm{O}_{2 \text { peak }}$ in either $\mathrm{CF}$ or CON groups. OUEP and $\mathrm{OUE}_{\mathrm{GET}}$, but not $\mathrm{OUE}_{\mathrm{RCP}}$, were correlated with allometrically scaled $\dot{V} \mathrm{O}_{2 \text { peak }}$ in both CF and CON (Table 2).

\section{Differences between aerobic fitness groups}

When the data were split by tertiles according to allometrically scaled $\dot{V} \mathrm{O}_{2 \text { peak }}$, a significant difference in aerobic fitness was observed between tertiles within both CF (high: $91.0 \pm 8.4$ vs. mid: $74.7 \pm 4.6$ vs. low: $58.1 \pm 7.5 \mathrm{~mL} \mathrm{~kg}^{-0.86}$. $\left.\min ^{-1}\right)$ and $\operatorname{CON}(110.1 \pm 16.3$ vs. $86.0 \pm 7.3$ vs. $\left.62.0 \pm 12.5 \mathrm{~mL} \mathrm{~kg}{ }^{-0.86} \cdot \mathrm{min}^{-1}\right)$ groups $(p<0.05$ for all

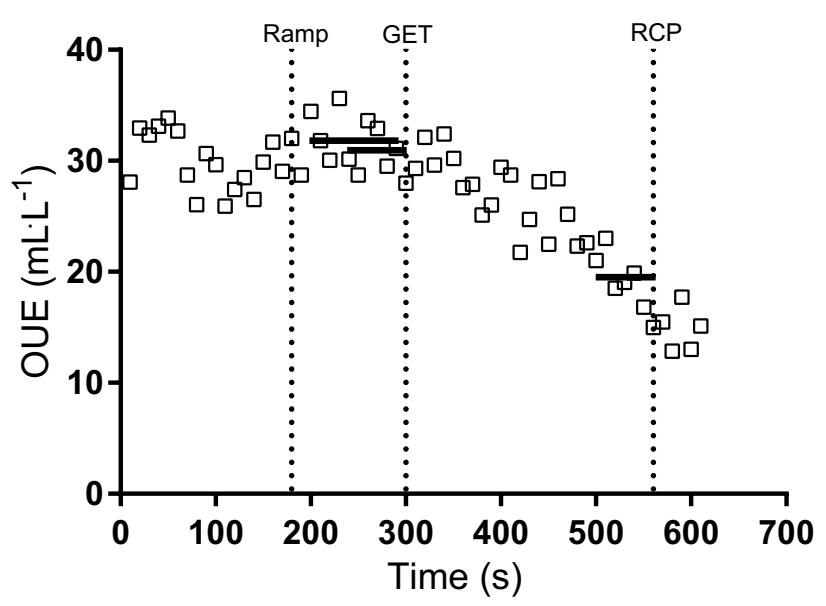

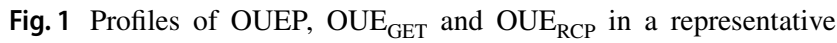
CPET from an individual child with $\mathrm{CF}$ (female, 12 years, homozygous $\Delta$ F508, $\mathrm{FEV}_{1} 82.0 \%$ predicted, $\dot{V} \mathrm{O}_{2 \text { peak }} 36.5 \mathrm{~mL} \mathrm{~kg}^{-1} \cdot \mathrm{min}^{-1}, 73.26$ $\left.\mathrm{mL} \mathrm{kg}{ }^{-0.86} \cdot \mathrm{min}^{-1}\right)$. Vertical line at $180 \mathrm{~s}$ indicates end of warm-up, and beginning of ramp phase. Vertical lines also indicate point of GET and RCP. Horizontal lines between 200-290 s=OUEP (31.9 $\left.\mathrm{mL} \mathrm{L}^{-1}\right), 240-300 \mathrm{~s}=\mathrm{OUE}_{\mathrm{GET}}\left(31.0 \mathrm{~mL} \mathrm{~L}^{-1}\right), 500-560 \mathrm{~s}=\mathrm{OUE}_{\mathrm{RCP}}$ (19.7 $\mathrm{mL} \mathrm{L}^{-1}$ ) 


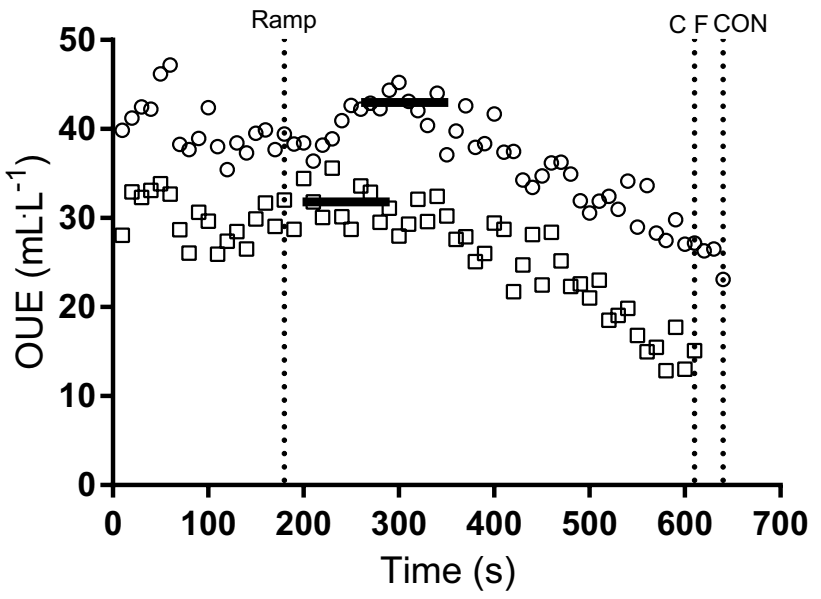

Fig. 2 Differences in OUE $\left(\dot{V}_{2} / \dot{V}_{\mathrm{E}}\right)$ between two representative children, $\mathrm{CF}$ (open square) and CON (open circle), throughout a ramp incremental CPET. Vertical line at $180 \mathrm{~s}$ indicates the end of the warm-up and beginning of ramp phase of the test. Vertical lines at 610 and $640 \mathrm{~s}$ indicate exhaustion for $\mathrm{CF}$ and CON participants, respectively. Solid horizontal lines at $31.9 \mathrm{~mL} \mathrm{~L}^{-1}(\mathrm{CF})$ and $43.0 \mathrm{~mL} \mathrm{~L}^{-1}(\mathrm{CON})$ indicate OUEP (highest $90 \mathrm{~s}$ average) for each group, respectively

pairwise comparisons, ES =1.91-4.13). However, when comparisons were made between groups, a significant difference in allometrically scaled $\dot{V} \mathrm{O}_{2 \text { peak }}$ between $\mathrm{CF}$ and $\mathrm{CON}$ was only evident in the high $(p<0.001, \mathrm{ES}=1.47)$ and middle $(p=0.50, \mathrm{ES}=1.85)$ aerobic fitness tertiles, not for the lowest $(p=0.39, \mathrm{ES}=0.38)$.

When assessing OUEP by fitness tertile and disease group, significant main effects were seen for group $(p<0.001)$ and fitness tertile $(p<0.001)$, but no significant fitness tertile by group interactions were evident $(p=0.20$; Fig. 4). Pairwise comparisons identified mean differences between CF and CON for OUEP at each level of fitness, respectively (high; $38.32 \pm 4.21$ vs. $50.26 \pm 5.22, p<0.001$, $\mathrm{ES}=2.52$, middle; $36.22 \pm 4.57$ vs. $43.19 \pm 5.06, p=0.001$, $\mathrm{ES}=1.45$, low; $32.19 \pm 5.73$ vs. $41.81 \pm 2.93, p<0.001$, $\mathrm{ES}=2.11$ ).

Mean differences for OUEP were found between the highest and lowest between aerobic fitness tertiles within $\mathrm{CF}(p=0.006, \mathrm{ES}=1.22)$, but not between high and middle $(p=0.62, \mathrm{ES}=0.48)$ nor middle and low $(p=0.11$, $\mathrm{ES}=0.78$ ). Further pairwise comparisons revealed differences within the CON group, as the tertile with the highest aerobic fitness had a significantly higher OUEP than the middle $(p=0.001, \mathrm{ES}=1.38)$ and lowest $(p<0.001$, $\mathrm{ES}=2.00)$ tertiles. No significant difference was evident between the middle and lowest tertiles with regard to OUEP for $\mathrm{CON}$ ( $p=0.85, \mathrm{ES}=0.33$; Fig. 4).

When ANOVAs were repeated for $\mathrm{OUE}_{\mathrm{GET}}$ and $\mathrm{OUE}_{\mathrm{RCP}}$, significant main effects for group were found $(p<0.001)$ for both parameters. Further significance $(p<0.05)$ between
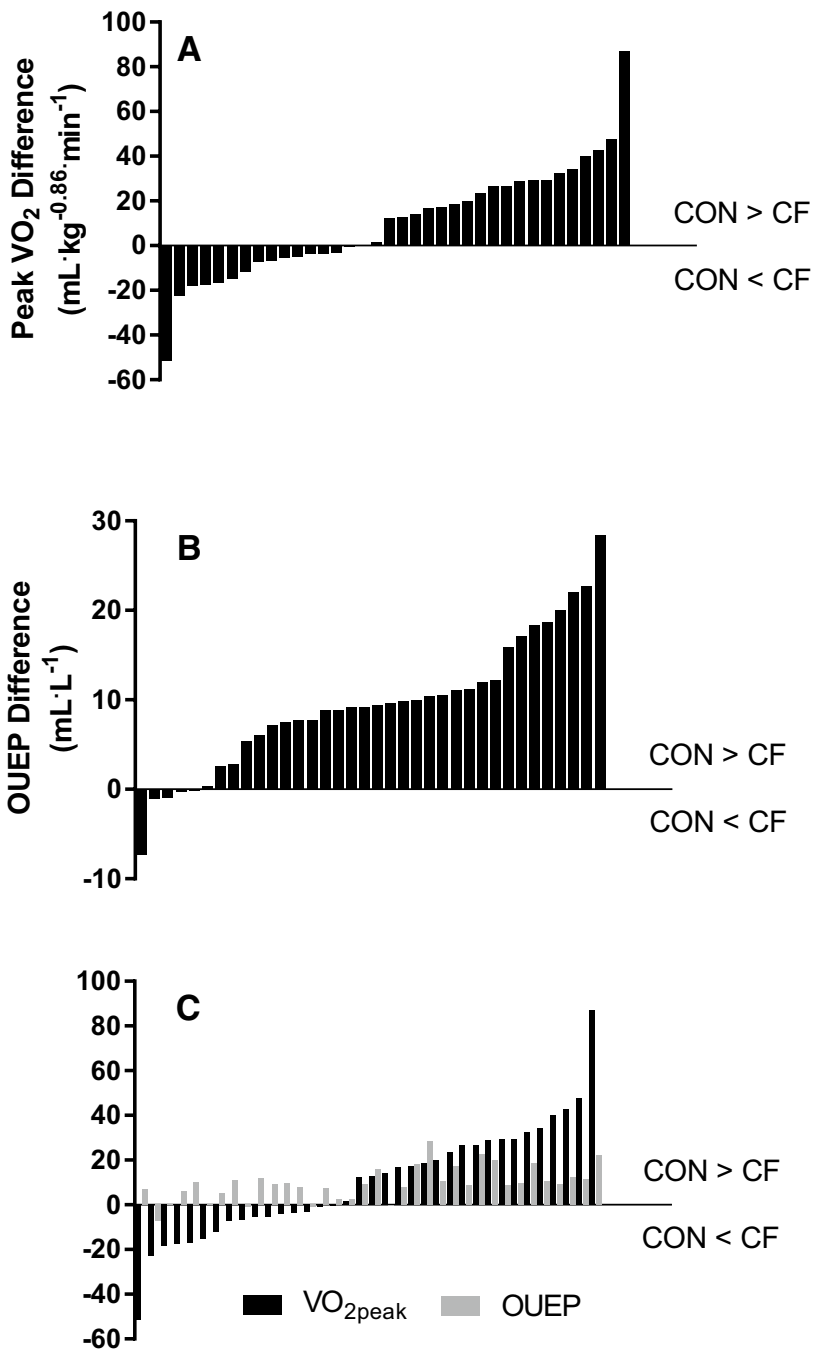

Fig. 3 Individual differences between age- and sex-matched CON and $\mathrm{CF}$ pairs for CPET-derived variables. All plots are calculated as CON minus $\mathrm{CF}$, i.e. bars underneath $y=0$ on $x$-axis indicate participant with $\mathrm{CF}$ has a greater value than CON counterpart. a Differences in allometrically scaled $\dot{V} \mathrm{O}_{2 \text { peak }}$ between pairs. b Differences in OUEP between pairs, independent of differences in $\dot{V} \mathrm{O}_{2 \text { peak }}$. c Differences in $\dot{V} \mathrm{O}_{2 \text { peak }}\left(\mathrm{mL} \mathrm{kg}^{-0.86} \cdot \mathrm{min}^{-1}\right)$ between pairs, plotted alongside withinpair differences in OUEP $\left(\mathrm{mL} \mathrm{L}^{-1}\right)$. Black bars represent $\dot{V} \mathrm{O}_{2 \text { peak }}$ and grey bars indicate OUEP

groups was identified when split by fitness tertile. A main effect for fitness tertile was present for $\mathrm{OUE}_{\mathrm{GET}}(p<0.001)$, but not $\operatorname{OUE}_{\mathrm{RCP}}(p=0.08)$. Main interaction effects between group and aerobic fitness were not present for either $\mathrm{OUE}_{\mathrm{GET}}$ $(p=0.34)$ or $\mathrm{OUE}_{\mathrm{RCP}}(p=0.88$; Fig. 4$)$. However, for OUE $_{\text {GET }}$, pairwise comparisons revealed significant differences within $\mathrm{CF}$ between high and low fitness tertiles $(p=0.021, \mathrm{ES}=1.01)$. For CON, differences were found between high and low $(p=0.002, \mathrm{ES}=1.48)$, and high and middle fitness tertiles $(p=0.026, \mathrm{ES}=1.15)$. For $\mathrm{OUE}_{\mathrm{RCP}}$, there were no differences between tertiles within groups 
Table 2 Correlations between OUE parameters and $\dot{V} \mathrm{O}_{2 \text { peak }}$, and $\mathrm{FEV}_{1}$

\begin{tabular}{|c|c|c|c|}
\hline & $\mathrm{CF}$ & $\mathrm{CON}$ & Combined \\
\hline \multicolumn{4}{|c|}{ Absolute $\dot{V} \mathrm{O}_{2 \text { peak }}\left(\mathrm{L} \mathrm{min}^{-1}\right)$} \\
\hline OUE $_{\mathrm{GET}}$ & $0.36(0.036)$ & $0.40(0.017)$ & $0.41(<0.001)$ \\
\hline $\mathrm{OUE}_{\mathrm{RCP}}$ & $0.12(0.50)$ & $0.29(0.09)$ & $0.28(0.022)$ \\
\hline OUEP & $0.43(0.010)$ & $0.42(0.010)$ & $0.44(<0.001)$ \\
\hline OUEP $(\%$ predicted $)$ & $0.22(0.20)$ & $0.12(0.51)$ & $0.24(0.040)$ \\
\hline \multicolumn{4}{|c|}{ Allometrically scaled $\dot{V} \mathrm{O}_{2 \text { peak }}\left(\mathrm{mL} \mathrm{kg}^{-0.86} \cdot \mathrm{min}^{-1}\right)$} \\
\hline OUE $_{\mathrm{GET}}$ & $0.49(0.003)$ & $0.46(0.005)$ & $0.51(<0.001)$ \\
\hline $\mathrm{OUE}_{\mathrm{RCP}}$ & $0.31(0.08)$ & $0.24(0.17)$ & $0.35(0.003)$ \\
\hline OUEP & $0.52(0.001)$ & $0.52(0.002)$ & $0.54(<0.001)$ \\
\hline OUEP $(\%$ predicted $)$ & $0.49(0.003)$ & $0.38(0.021)$ & $0.47(<0.001)$ \\
\hline \multicolumn{4}{|l|}{$\mathrm{FEV}_{1}\left(\%_{\text {predicted }}\right) *$} \\
\hline OUE $_{\mathrm{GET}}$ & $0.38(0.026)$ & $-0.06(0.83)$ & $0.44(0.001)$ \\
\hline $\mathrm{OUE}_{\mathrm{RCP}}$ & $0.07(0.68)$ & $0.14(0.61)$ & $0.24(0.08)$ \\
\hline OUEP & $0.43(0.010)$ & $-0.20(0.43)$ & $0.43(0.001)$ \\
\hline OUEP (\% predicted) & $0.46(0.005)$ & $-0.19(0.45)$ & $0.44(0.001)$ \\
\hline
\end{tabular}

Values are presented as correlation coefficients $(r)$ with $p$ values in parentheses. Bold text indicates a significant $(p<0.05)$ coefficient $\dot{V} O_{2}$ oxygen uptake, $F E V_{1}$ forced expiratory volume in 1 second *Unequal samples for pulmonary variables: $\mathrm{CF}=36, \mathrm{CON}=18$

$(p=0.37-1.00, \mathrm{ES}=0.01-0.86)$. In addition, pairwise comparisons revealed significant differences $(p<0.05)$ between groups at each tertile for both $\mathrm{OUE}_{\mathrm{GET}}$ and $\mathrm{OUE}_{\mathrm{RCP}}$ (Fig. 4).

\section{Relationship with disease severity $\left(\mathrm{FEV}_{1}\right)$}

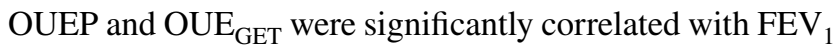
within the $\mathrm{CF}$ group, but $\mathrm{OUE}_{\mathrm{RCP}}$ was not. None of the OUE parameters were significantly correlated with $\mathrm{FEV}_{1}$ within CON (Table 2). Allometrically scaled $\dot{V} \mathrm{O}_{2 \text { peak }}$ was significantly correlated with $\mathrm{FEV}_{1}\left(\%_{\text {predicted }}\right)$ in $\mathrm{CF}(r=0.46$, $p=0.004)$, but not CON $(r=-0.20, p=0.43)$.

\section{Discussion}

In this study, whilst all OUE parameters were significantly reduced in children and adolescents with $\mathrm{CF}$ in the current study, results show that OUE does not provide a viable surrogate for $\dot{V} \mathrm{O}_{2 \text { peak }}$ in this group. However, the novel finding of this study is that OUE appears to hold clinical utility as an independent marker of aerobic fitness, since it can differentiate between CF and CON, and holds a significant relationship with disease severity (as shown by $\mathrm{FEV}_{1}$ ) in the CF group. An example is shown in Fig. 3, whereby allometrically scaled $\dot{V} \mathrm{O}_{2 \text { peak }}$ was greater in individuals with CF in 16/36 (44\%) age- and sex-matched pairs, but OUEP was only greater in individuals with $\mathrm{CF}$
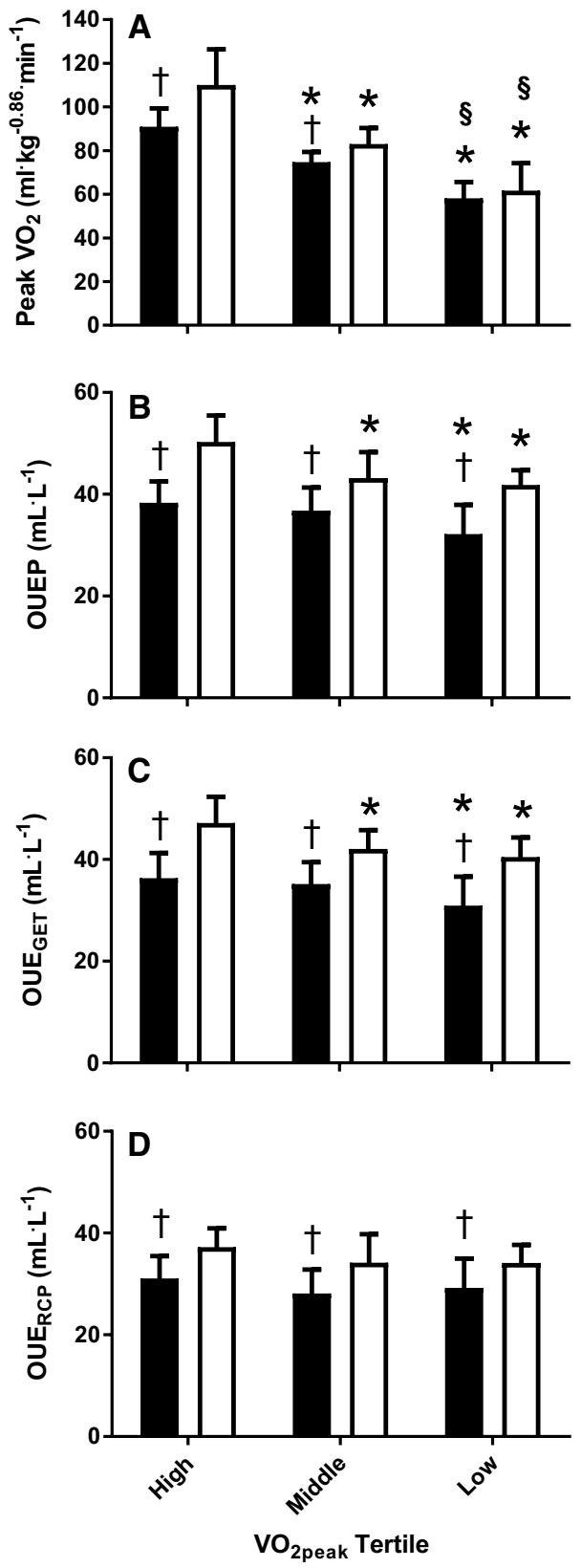

Fig. 4 Comparison of $\dot{V} \mathrm{O}_{2 \text { peak }}$ (a) and OUE parameters (b OUEP; $\mathbf{c}$ $\mathrm{OUE}_{\mathrm{GET}} ; \mathbf{d} \mathrm{OUE}_{\mathrm{RCP}}$ ) between CF (black) and CON (white), split by $\dot{V} \mathrm{O}_{2 \text { peak }}$ tertile. ${ }^{*}$ Significant $(p<0.05)$ difference from highest tertile (within group). ${ }^{\S}$ Significant $(p<0.05)$ difference from middle tertile (within group). ${ }^{\dagger}$ Significant $(p<0.05)$ difference between groups (within tertile)

in $5 / 36(14 \%)$ matched pairs [and $\dot{V} \mathrm{O}_{2 \text { peak }}$ and OUEP were only greater in $\mathrm{CF}$ in $4 / 36(11 \%)$ of cases], thus indicating reduced OUE in CF, regardless of fitness status. This is further corroborated by the significant relationship between OUE (OUEP, OUE $\mathrm{GET})$ and $\mathrm{FEV}_{1}\left(\%_{\text {predicted }}\right)$ within the CF cohort, showing that OUE is associated with traditional clinical markers of disease severity. 
For individuals with $\mathrm{CF}$, a reduced aerobic fitness is a hallmark of disease progression (Orenstein and Higgins 2005) and assessment of $\dot{V} \mathrm{O}_{2 \text { peak }}$ is, therefore, recommended on at least an annual basis (Hebestreit et al. 2015). However, as maximal testing may not always be possible in this patient group (due to pathophysiological and/or motivation related factors), viable submaximal measures are needed to assess aerobic fitness. Whilst submaximal physiological thresholds such as the GET are related to disease severity (Thin et al. 2002), detection rates are variable in CF $[12 / 13 ; 92 \%$ (Saynor et al. 2013b)], and non-CF [45/55; 82\% (Hebestreit et al. 2000)] groups and are typically dependent on knowledge of $\dot{V} \mathrm{O}_{2 \text { peak }}$ to be expressed as a percentage of maximal capacity. In the present study, all OUE values were identified in the majority (94\%) of participants, with OUEP identified in $100 \%$ of participants. The identification of OUEP is related to the averaging of $90 \mathrm{~s}$ of data and is not dependent on prior detection of the GET or RCP (to produce $\mathrm{OUE}_{\mathrm{GET}}$ and $\left.\mathrm{OUE}_{\mathrm{RCP}}\right)$. The OUEP occurs at a submaximal point near the VT (Bongers et al. 2015) and/or GET (Sun et al. 2012b), a threshold that reportedly occurs at $50-60 \%$ of $\dot{V} \mathrm{O}_{2 \text { peak }}$ in children and adolescents with CF (Bongers et al. 2014b; Saynor et al. 2014, 2016). Therefore, the exercise intensity required to generate a value for OUEP should be feasible for most children to achieve despite being unable or unwilling to exercise to exhaustion, such as those with advanced pulmonary disease, or more prone to increased levels of dyspnoea and desaturation upon exertion. The simplicity of the OUEP measure highlights how feasible a measure it may be to implement in busy clinical environments, suiting patients, researchers and clinicians alike.

In the current study, OUE variables were significantly correlated with $\dot{V} \mathrm{O}_{2 \text { peak }}$ in the $\mathrm{CON}$ and CF groups, indicating the two variables have a medium [as defined by Cohen (1992)] relationship $\left(R^{2}=27 \%\right.$ between OUEP and allometrically scaled $\dot{V} \mathrm{O}_{2 \text { peak }}$ in both $\mathrm{CF}$ and $\left.\mathrm{CON}\right)$. Given previous research (Williams et al. 2018) has identified differences in $\dot{V} \mathrm{O}_{2 \text { peak }}$ within, and between, $\mathrm{CF}$ and $\mathrm{CON}$ groups when split by aerobic fitness tertile, a division shown to predict for mortality (Pianosi et al. 2005), it would, therefore, be anticipated that parameters of OUE would follow a similar pattern in discriminating between individuals' of differing aerobic fitness statuses. Differences are seen within the CON group for OUEP, with the highest fitness tertile having significantly greater OUEP relative to children in the middle and lowest fitness tertiles, thus, showing that OUEP can discriminate between individuals on different fitness status. However, the same discriminatory ability is not seen for the CF group as it is only the group with the lowest aerobic fitness that is different to the group with the highest fitness (Fig. 4). Therefore, despite a relationship with $\dot{V} \mathrm{O}_{2 \text { peak }}$, the inability to discriminate between the fitness groups shows that the OUEP cannot act as a surrogate for $\dot{V} \mathrm{O}_{2 \text { peak }}$.
Of the limited research to have characterised the OUEP in youth, a large cross-sectional study of 214 healthy Dutch children identified similar mean values for OUEP (boys, $42.6 \pm 4.7$; girls, $42.3 \pm 4.6 \mathrm{~mL} \mathrm{~L}^{-1}$ ) and OUE at the VT (boys, $42.0 \pm 4.6$; girls, $41.9 \pm 4.7 \mathrm{~mL} \mathrm{~L}^{-1}$ ) to those of the CON group in the current study (Bongers et al. 2015). They also identified a stronger relationship $(r=0.65$, $p<0.01)$ between the OUEP and absolute $\dot{V} \mathrm{O}_{2 \text { peak }}$ than the CON group in the current study, potentially due to the higher $\dot{V}_{\text {Emax }}$ observed in both boys and girls $(80 \pm 25$; $71 \pm 21 \mathrm{~L} \mathrm{~min}^{-1}$ respectively) relative to the current $\mathrm{CON}$ group $\left(69.2 \pm 33.5 \mathrm{~L} \mathrm{~min}^{-1}\right)$, which may, therefore, bias the relationship between $\dot{V} \mathrm{O}_{2}$ and $\dot{V} \mathrm{O}_{2} / \dot{V}_{\mathrm{E}}$ (OUE). However, as the current study builds upon this previous work and is the first to comprehensively examine OUE at multiple metabolic thresholds in children and adolescents with CF, only limited comparisons can be made, as no previous research has provided values against which to compare our novel data. Furthermore, the only application of OUE in clinical groups has been in adults with heart failure (Sun et al. 2012a), pulmonary hypertension (Tan et al. 2014), chronic obstructive pulmonary disease (Barron et al. 2016) and pulmonary embolism (Guo et al. 2016). However, minimal comparisons and inferences can be made against children with $\mathrm{CF}$ and these adult-onset, and predominantly vascular conditions.

As the current study has shown that OUEP (nor any OUE parameter) is not able to act as a surrogate measure of aerobic fitness, alternative submaximal factors must be considered. Ventilatory drive $\left(\dot{V}_{\mathrm{E}} / \dot{V} \mathrm{CO}_{2}\right)$ has received recent attention in predictive models of mortality (Hulzebos et al. 2014), and may be a viable candidate, given its low variability compared to $\dot{V}_{\mathrm{E}} / \dot{V} \mathrm{O}_{2}$ (Sun et al. 2002) and superior prognostic value relative to OUES in patients with heart failure (Arena et al. 2007). As such, further research should continue to explore the potential utility of this variable in individuals with $\mathrm{CF}$, either as an alternative for $\dot{V} \mathrm{O}_{2 \text { peak }}$, or an independent prognostic variable. However, it is unclear whether any parameter of OUE may be of use in individuals with a more severe form of $\mathrm{CF}$, or have longitudinal relevance in mildto-moderate $\mathrm{CF}$ and, therefore, further research is warranted.

A number of limitations associated with the present study are worthy of comment. Primarily, this study is focused in children and adolescents with mild-to-moderate $\mathrm{CF}$ $\left(\mathrm{FEV}_{1}>40 \%_{\text {predicted }}\right)$. However, defining severity on $\mathrm{FEV}_{1}$ alone does not account for the nutritional measures, number of exacerbations, inflammatory markers and infection statuses that also contribute towards a patient profile and definition of severity. Consequently, these results may not be applicable to those with lower lung function, a cohort for whom $\mathrm{FEV}_{1}$ has a greater influence upon $\dot{V} \mathrm{O}_{2 \text { peak }}$ (Pastre et al. 2014). Furthermore, the CON group in the current study displays a reduced level of aerobic fitness relative to previous studies investigating OUE (Bongers et al. 2015), 
which may explain the number of individuals with CF having a higher $\dot{V} \mathrm{O}_{2 \text { peak }}$ within age- and gender-matched pairs (Fig. 3). In addition, the lack of all participants undertaking supramaximal verification bouts (Barker et al. 2011) within CPETs could potentially influence detection of a 'true' $\dot{V} \mathrm{O}_{2 \max }$ (hence our use of $\dot{V} \mathrm{O}_{2 \text { peak }}$ ). This is likely to have minimal effect, as previous work has shown that the ramp-only test elicits a 'true' $\dot{V} \mathrm{O}_{2 \max }$ in $\sim 90 \%$ of healthy children (Barker et al. 2011) and $~ 80 \%$ of children with CF (Saynor et al. 2013a). Finally, when these methodological issues are considered in conjunction with our sample size, true effects may be obscured regarding the ability for OUEP to discriminate aerobic fitness. For example, the difference between middle- and low-fitness tertiles in CF revealed a $p$ value of 0.11 , yet an ES of 0.78 , thus indicating an effect is likely present but cannot be statistically confirmed. We have utilised the Sidak correction factor in this study as opposed to the more conservative Bonferroni in an attempt to alleviate the potential for Type 2 errors, yet statistical significance was not found in some comparisons and a statistical error might still have occurred. Larger clinical sample sizes would be advantageous but are not always feasible in young people who are sick.

\section{Conclusion}

The current study is the first to comprehensively characterise parameters of OUE in children and adolescents with mildto-moderate $\mathrm{CF}$, and assess the utility of such parameters as submaximal surrogates for $\dot{V} \mathrm{O}_{2 \text { peak }}$. Despite promising findings in other clinical populations, and a significant relationship between OUE and allometrically scaled $\dot{V} \mathrm{O}_{2 \text { peak }}$ in the present study, the inability to differentiate between aerobic fitness statuses indicates that OUE is unable to provide a viable surrogate for $\dot{V} \mathrm{O}_{2 \text { peak }}$ in this population. Further research is, therefore, warranted to identify suitable submaximal variables to characterise aerobic fitness status in children and adolescents with CF when determination of $\dot{V} \mathrm{O}_{2 \text { peak }}$ is not possible. Moreover, the prognostic utility of OUE in $\mathrm{CF}$ when $\dot{V} \mathrm{O}_{2 \text { peak }}$ cannot be determined also warrants investigation.

Acknowledgements The authors would like to thank the patients and staff at the Royal Devon and Exeter NHS Foundation Trust Hospital. Additional appreciation is given to Mr. James Shelley and Dr. Emma Cockcroft for their assistance with data collection.

Author contributions OWT, DS and ZLS collected data, and OWT and LVC analysed data, all under supervision of CAW (principal investigator), ARB and PJO. OWT drafted the manuscript. ARB, DS, ZLS, PJO and CAW reviewed and edited the draft. All authors have read and approved the work.
Funding Funding for the original research was provided by a number of Royal Devon and Exeter NHS Foundation Trust Small Grants Fund. In addition, LV Chubbock was awarded a summer scholarship by the Cystic Fibrosis Trust to undertake some of the data analysis for this study.

\section{Compliance with ethical standards}

Conflict of interest LVC is currently an employee of Springer Nature, but was solely associated with the University of Exeter at the time that the research was conducted.

Open Access This article is distributed under the terms of the Creative Commons Attribution 4.0 International License (http://creativeco mmons.org/licenses/by/4.0/), which permits unrestricted use, distribution, and reproduction in any medium, provided you give appropriate credit to the original author(s) and the source, provide a link to the Creative Commons license, and indicate if changes were made.

\section{References}

Abdi H (2007) The Bonferonni and Šidák corrections for multiple comparisons. In: Salkind N (ed) Encyclopedia of measurement and statistics. Sage, Thousand Oaks, pp 103-107

Arena R, Myers J, Hsu L, Peberdy MA, Pinkstaff S, Bensimhon D, Chase P, Vicenzi M, Guazzi M (2007) The minute ventilation/ carbon dioxide production slope is prognostically superior to the oxygen uptake efficiency slope. J Cardiac Fail 13(6):462-469. https://doi.org/10.1016/j.cardfail.2007.03.004

Baba R, Nagashima M, Goto M, Nagano Y, Yokota M, Tauchi N, Nishibata K (1996) Oxygen uptake efficiency slope: a new index of cardiorespiratory functional reserve derived from the relation between oxygen uptake and minute ventilation during incremental exercise. J Am Coll Cardiol 28(6):1567-1572. https://doi. org/10.1016/S0735-1097(96)00412-3

Barker AR, Williams CA, Jones AM, Armstrong N (2011) Establishing maximal oxygen uptake in young people during a ramp cycle test to exhaustion. Br J Sports Med 45(6):498-503. https://doi. org/10.1136/bjsm.2009.063180

Barron A, Francis DP, Mayet J, Ewert R, Obst A, Mason M, Elkin S, Hughes AD, Wensel R (2016) Oxygen uptake efficiency slope and breathing reserve, not anaerobic threshold, discriminate between patients with cardiovascular disease over chronic obstructive pulmonary disease. JACC Heart Fail 4(4):252-261. https://doi. org/10.1016/j.jchf.2015.11.003

Beaver WL, Wasserman K, Whipp BJ (1986) A new method for detecting anaerobic threshold by gas exchange. J Appl Physiol 60(6):2020-2027

Bongers BC, van Brussel M, Hulzebos EHJ, Takken T (2014a) Pediatric norms for cardiopulmonary exercise testing, 2nd edn. Uitgeverij BOXPress, "s-Herogenbosch

Bongers BC, Werkman MS, Takken T, Hulzebos EH (2014b) Ventilatory response to exercise in adolescents with cystic fibrosis and mild-to-moderate airway obstruction. SpringerPlus 3:696. https:// doi.org/10.1186/2193-1801-3-696

Bongers BC, Hulzebos EH, Helbing WA, Ten Harkel AD, van Brussel M, Takken T (2015) Response profiles of oxygen uptake efficiency during exercise in healthy children. Eur J Prev Cardiol. https://doi. org/10.1177/2047487315611769

Cohen J (1992) A power primer. Psychol Bull 112(1):155-159. https ://doi.org/10.1037/0033-2909.112.1.155 
Fawkner SG, Armstrong N, Childs DJ, Welsman JR (2002) Reliability of the visually identified ventilatory threshold and v-slope in children. Pediatr Exerc Sci 14(2):181-192. https://doi.org/10.1123/ pes.14.2.181

Gruet M, Brisswalter J, Mely L, Vallier JM (2010) Clinical utility of the oxygen uptake efficiency slope in cystic fibrosis patients. J Cyst Fibros 9(5):307-313. https://doi.org/10.1016/j.jcf.2010.03.003

Guo J, Chen S, Pudasaini B, Zhao Q, Yang W, Wang L, Gong S, Liu J (2016) Oxygen uptake efficiency slope, an objective submaximal parameter in evaluating exercise capacity in pulmonary thromboembolism. Am J Med Sci 351(5):485-491. https://doi. org/10.1016/j.amjms.2016.02.028

Haycock GB, Schwartz GJ, Wisotsky DH (1978) Geometric method for measuring body surface area: a height-weight formula validated in infants, children, and adults. J Pediatr 93(1):62-66. https://doi. org/10.1016/s0022-3476(78)80601-5

Hebestreit H, Staschen B, Hebestreit A (2000) Ventilatory threshold: a useful method to determine aerobic fitness in children? Med Sci Sports Exerc 32(11):1964-1969

Hebestreit H, Schmid K, Kieser S, Junge S, Ballmann M, Roth K, Hebestreit A, Schenk T, Schindler C, Posselt HG, Kriemler S (2014) Quality of life is associated with physical activity and fitness in cystic fibrosis. BMC Pulm Med 14:26. https://doi. org/10.1186/1471-2466-14-26

Hebestreit H, Arets HG, Aurora P, Boas S, Cerny F, Hulzebos EH, Karila C, Lands LC, Lowman JD, Swisher A, Urquhart DS, European Cystic Fibrosis Exercise Working Group (2015) Statement on exercise testing in cystic fibrosis. Respiration 90(4):332-351. https://doi.org/10.1159/000439057

Hulzebos EH, Bomhof-Roordink H, van de Weert-van Leeuwen PB, Twisk JW, Arets HG, van der Ent CK, Takken T (2014) Prediction of mortality in adolescents with cystic fibrosis. Med Sci Sports Exerc 46(11):2047-2052. https://doi.org/10.1249/MSS.00000 00000000344

Nixon PA, Orenstein DM, Kelsey SF, Doershuk CF (1992) The prognostic value of exercise testing in patients with cystic fibrosis. $\mathrm{N}$ Engl J Med 327(25):1785-1788. https://doi.org/10.1056/NEJM1 99212173272504

Orenstein DM, Higgins LW (2005) Update on the role of exercise in cystic fibrosis. Curr Opin Pulm Med 11(6):519-523

Pastre J, Prevotat A, Tardif C, Langlois C, Duhamel A, Wallaert B (2014) Determinants of exercise capacity in cystic fibrosis patients with mild-to-moderate lung disease. BMC Pulm Med 14:74. https ://doi.org/10.1186/1471-2466-14-74

Pérez M, Groeneveld IF, Santana-Sosa E, Fiuza-Luces C, GonzalezSaiz L, Villa-Asensi JR, López-Mojares LM, Rubio M, Lucia A (2014) Aerobic fitness is associated with lower risk of hospitalization in children with cystic fibrosis. Pediatr Pulmonol 49(7):641649. https://doi.org/10.1002/ppul.22878

Pianosi P, LeBlanc J, Almudevar A (2005) Peak oxygen uptake and mortality in children with cystic fibrosis. Thorax 60(1):50-54. https://doi.org/10.1136/thx.2003.008102

Quanjer PH, Stanojevic S, Cole TJ, Baur X, Hall GL, Culver BH, Enright PL, Hankinson JL, Ip MS, Zheng J, Stocks J, Initiative ERSGLF (2012) Multi-ethnic reference values for spirometry for the 3-95-yr age range: the global lung function 2012 equations. Eur Respir J 40(6):1324-1343. https://doi.org/10.1183/09031 936.00080312

Saynor ZL, Barker AR, Oades PJ, Williams CA (2013a) A protocol to determine valid $\mathrm{VO}_{2 \max }$ in young cystic fibrosis patients. $\mathrm{J}$
Sci Med Sport 16(6):539-544. https://doi.org/10.1016/j.jsams .2013.01.010

Saynor ZL, Barker AR, Oades PJ, Williams CA (2013b) Reproducibility of maximal cardiopulmonary exercise testing for young cystic fibrosis patients. J Cyst Fibros 12(6):644-650. https://doi. org/10.1016/j.jcf.2013.04.012

Saynor ZL, Barker AR, Oades PJ, Williams CA (2014) Impaired aerobic function in patients with cystic fibrosis during ramp exercise. Med Sci Sports Exerc 46(12):2271-2278. https://doi.org/10.1249/ MSS.0000000000000369

Saynor ZL, Barker AR, Oades PJ, Williams CA (2016) Impaired pulmonary $\mathrm{VO}_{2}$ kinetics in cystic fibrosis depend on exercise intensity. Med Sci Sports Exerc 48(11):2090-2099. https://doi. org/10.1249/MSS.0000000000001004

Sun XG, Hansen JE, Garatachea N, Storer TW, Wasserman K (2002) Ventilatory efficiency during exercise in healthy subjects. Am J Respir Crit Care Med 166(11):1443-1448. https://doi. org/10.1164/rccm.2202033

Sun XG, Hansen JE, Stringer WW (2012a) Oxygen uptake efficiency plateau best predicts early death in heart failure. Chest 141(5):1284-1294. https://doi.org/10.1378/chest.11-1270

Sun XG, Hansen JE, Stringer WW (2012b) Oxygen uptake efficiency plateau: physiology and reference values. Eur J Appl Physiol 112(3):919-928. https://doi.org/10.1007/s00421-011-2030-0

Tan X, Yang W, Guo J, Zhang Y, Wu C, Sapkota R, Kushwaha SP, Gong S, Sun X, Liu J (2014) Usefulness of decrease in oxygen uptake efficiency to identify gas exchange abnormality in patients with idiopathic pulmonary arterial hypertension. PLoS One 9(6):e98889. https://doi.org/10.1371/journal.pone.0098889

Thin AG, Linnane SJ, McKone EF, Freaney R, FitzGerald MX, Gallagher CG, McLoughlin P (2002) Use of the gas exchange threshold to noninvasively determine the lactate threshold in patients with cystic fibrosis. Chest 121(6):1761-1770. https:// doi.org/10.1378/chest.121.6.1761

Tomlinson OW, Barker AR, Oades PJ, Williams CA (2017) Scaling the oxygen uptake efficiency slope for body size in cystic fibrosis. Med Sci Sports Exerc 49(10):1980-1986. https://doi.org/10.1249/ MSS.0000000000001314

Wasserman K, Hansen JE, Sue DY, Stringer WW, Whipp BJ (2005) Principles of exercise testing and interpretation. Lippincott Williams \& Wilkin, Philadelphia

Welsman JR, Armstrong N, Nevill AM, Winter EM, Kirby BJ (1996) Scaling peak $\mathrm{VO}_{2}$ for differences in body size. Med Sci Sports Exerc 28(2):259-265

Welsman J, Bywater K, Farr C, Welford D, Armstrong N (2005) Reliability of peak $\mathrm{VO}(2)$ and maximal cardiac output assessed using thoracic bioimpedance in children. Eur J Appl Physiol 94(3):228234. https://doi.org/10.1007/s00421-004-1300-5

Williams CA, Saynor ZL, Tomlinson OW, Barker AR (2014) Cystic fibrosis and physiological responses to exercise. Expert Rev Respir Med 8(6):751-762. https://doi.org/10.1586/17476 348.2014.966693

Williams CA, Tomlinson OW, Chubbock LV, Stevens D, Saynor ZL, Oades PJ, Barker AR (2018) The oxygen uptake efficiency slope is not a valid surrogate of aerobic fitness in cystic fibrosis. Pediatr Pulmonol 53(1):36-42. https://doi.org/10.1002/ppul.23896 